\title{
Small things with big impact in urban infrastructure design
}

\section{Sara Adhitya* and Nick Tyler}

Department of Civil, Environmental and Geomatic Engineering,

University College London,

Chadwick Building, Gower Street,

WC1E6BT, London, UK

Email: s.adhitya@ucl.ac.uk

Email: n.tyler@ucl.ac.uk

*Corresponding author

\begin{abstract}
In cities, infrastructure is usually considered to include energy, transportation, communications, waste and other large-scale systems that support its operation. However, in the design of these systems, we often forget that these infrastructure systems operate is largely dependent on the small-scale interactions between the people and the infrastructure. These people-environment interactions are crucial to the success of the infrastructure in supporting the wellbeing of both society and the individual. This paper examines people-environment interactions in street-based transportation - such as walking, waiting and lingering in the urban space - to examine the importance of such interactions in the successful operation of the public transport system. It explores how personal interactions can be enhanced by paying closer attention to details of urban design in London and the cities of Panama, Santa Marta and Barranquilla in Latin America, and discusses various interventions where the local community can be involved in improving such interactions.
\end{abstract}

Keywords: cities; urban infrastructure systems; public transport system; bus stops; urban design; people-environment interactions; urban interaction design; public engagement; wellbeing; walking; waiting; lingering.

Reference to this paper should be made as follows: Adhitya, S. and Tyler, N. (2016) 'Small things with big impact in urban infrastructure design', Int. J. Complexity in Applied Science and Technology, Vol. 1, No. 1, pp.61-85.

Biographical notes: Sara Adhitya is an urban designer with a multidisciplinary background in environmental design, architecture, urbanism, music and sound design. She collaborates with design, research and governmental organisations around the world towards improving the quality of our urban environments. Awarded a European doctorate in the 'Quality of Design' of architecture and urban planning, she is concerned with the composition of more sustainable urban rhythms. She is currently a Research Associate at University College London, where she is developing the concept of Universal Composition - the multisensorial design of our environment in space and time - while advancing interdisciplinary university education.

Nick Tyler is the Chadwick Professor of Civil Engineering at UCL. He was the Head of Department of Civil, Environmental and Geomatic Engineering at UCL from 2003 to 2013. Currently, he researches the environment's interactions with people. He is working extensively with bodies such as Transport for London in the UK, Latin America, Japan and China on creating 
an urban realm which is responsive to people and their needs. He is a keen advocate of transdisciplinary research and works with neurologists, health practitioners, musicians, artists, psychologists, economists, social, natural and life scientists as well as with architects and engineers to create a better world.

This paper is a revised and expanded version of a paper entitled 'It's the little things that count...' presented at the International Symposium for Next Generation Infrastructure, Vienna, 30 September to 1 October 2014.

\section{Introduction}

All too often, when thinking about infrastructure, people think about large-scale systems - railways, bridges, communications, energy, transport, health systems and so on - which are much larger than a human body. However, it is useful to pause for a moment to think about the purpose of infrastructure. The word means "that which lies underneath and supports a structure" (OED, 1989) and in the context of interactions between infrastructure and people, this includes the support for the structure of society as well as support for structures such as buildings, transport or communications systems. Thus, infrastructure has an important role to play in the improvement of quality of life and the achievement of societal wellbeing. Quality of life is a concept that is tied to individual people, so it is important to see how infrastructure, which is usually considered to be supporting much larger entities interacts with individual people to achieve this outcome. So a first task is to scale down from the large-scale (e.g. a city) to the small-scale (e.g. a person), so that we can see how such interactions might be designed. In order to obtain societal wellbeing, infrastructure design must first address how individuals encounter infrastructure and the implications these encounters have for both the people and the infrastructure system itself. It is therefore incumbent upon those who are concerned with the development of city systems, to address explicitly the interactions between people and their infrastructure.

This paper will discuss infrastructure in terms of people-environment interactions and the design of the little things that help determine their success. We take examples from London and Latin America, where we have used interventions in the urban realm to change people's perceptions of the street-transport infrastructure to illustrate how this could be achieved.

\section{People-environment interactions}

With societal wellbeing being dependent on our people-environment interactions, first we explore what these interactions are. Two factors that need to be understood when considering the interface between people and the environment are the way in which a person perceives the environment and the fact that the environment changes over time. 


\subsection{Perception of 'environment'}

It is important to realise that what is loosely called 'the environment' is something which is experienced by individuals through their many senses in a highly personal way. Our perception of the environment thus varies depending on our sensorial capabilities. At the basic level it is each individual who creates their own interaction with the immediate environment, making the design of its details extremely important to the resulting experience of a city. However, sensorial capabilities vary between people - some may lack a sense or have senses which change over time, while others could even be synaesthetic and sense things in a different way. Yet in designing large-scale infrastructure systems, we are dealing with the interactions of many individuals, which both vary from one to another and influence each other. Thus, sensorial design must address the single experience of one person as well as the more general experience of many.

We need to consider both the range of sensorial capabilities and their relationship to each other. By considering the range of environmental stimuli on offer in our design, we can begin to address the senses of more people and thus design more inclusively. However, in designing them, we should also consider the impact of spatial, cultural and climatic features which will inevitably influence the way in which they are perceived. These stimuli could lead to positive emotions, such as friendliness in lively public spaces, or instigate more negative emotions, such as fear in dark, unlit alleys. Thus in designing people-environment interactions, we need to factor in the relevant stimuli conducive to certain emotions, which are at once both 'personal' and 'universal'. As we understand our environments through both individual and collective sensorial interactions, the multisensorial design of our infrastructure systems can make them easier to perceive and thus more understandable, navigable and accessible to more people.

\subsection{Temporal environments}

Whatever we may design in space will inevitably change over time as our urban environments are in a continual state of change. Every time a person walks through a certain street or waits in a certain place, the colours, movements, sounds, images and lighting will be different. This is due to various factors, including the seasons or time of day. However, one of the main examples of this change is people. In an urban streetscape, people will be walking in different directions and at different speeds, be waiting at different points for other people or public transport infrastructure, or be lingering in different public spaces. Thus in an instant, other people actually become part of the infrastructure with which one person interacts. At another point in time, these people are somewhere else, and the environment is a different one. Yet there is a tendency to design the environment as though it were somehow permanent and unchanging. If we want to improve people-environment interactions, we need to incorporate these temporal changes explicitly into our design. When designing our infrastructure, we need to acknowledge the environment as being dynamic.

Another important aspect of time is that our perception of it is not constant. For example, a minute could be perceived to be two or three times as long as, or much shorter than, the time recorded by a clock and in terms of how people respond to time, it is this perception that actually matters (Tyler, in press). This has direct consequences on our perception of our urban infrastructure systems and our behaviour towards them. One 
situation in which this is paramount for the success of the infrastructure system is how long we are willing to wait for public transport.

Given that the environment is continually changing over time, and our perception of that time is not constant, it is important to consider the environment as a process as well as a product: in this view, urban infrastructure provides the theatre for which our lives play out over time and we need to design for these temporal changes as well as their spatial setting. In effect, we are approaching the design of the city in the manner of composing a play or an opera, as much as we are designing the technical details of the infrastructure.

\section{The 'universal composition' approach}

In order to address these design parameters, which define the relationship between people and their environments, we have developed the approach of universal composition - the multisensorial design of the environment in space and time. This refers to the compositional processes by which more 'temporal' art forms such as music, poetry, or dance achieve their objective through the blend of different sensorial stimuli in both space and time. This can be applied to 'static' art forms such as built form and hard transport infrastructure, which in effect are temporal in their composition of movement and experience. It considers elements of the environment as both a product and a process, rather than one or the other. It aims to be universal by catering for the range of senses of individuals to be both inclusive and accessible to as many people as possible.

The universal composition approach emphasises the actual interaction between a person and their immediate environment - for example, how they hear it, see it, feel it. This means that it is crucial to consider the small details of the environment, not only in the sense of the small elements of the system (e.g. a lamp pole or bus stop) but also the sensorial details of those elements (e.g. their colour, sound and feel). We argue that by paying greater attention to these small but numerous elements of the environmental infrastructure, great behavioural change can be achieved with respect to the usage of infrastructure systems, through their sheer number and far-reaching distribution. London, for example, has almost 20,000 bus stops across the metropolitan area, and small changes to improve our interaction with them can thus yield a great difference in pedestrian/ passenger behaviour across the network, as well as affect other urban.

Thus two important characteristics of the environment are the fact that personenvironment interactions are multisensorial, and that they will inevitably change over time. These factors should be integral to the design of our infrastructure systems.

\section{Composing our urban infrastructure}

In the following sections we will investigate how we can compose for two human activities which are essential to any transport infrastructure system - walking and waiting - by applying the principles of universal composition. With the aim to use the infrastructure system to improve the overall design of the urban realm and create inviting places for people, we will also discuss a third important activity: lingering. 


\subsection{Composing for walking}

In order to compose for walking, we must consider our perception of speed and the important role infrastructure has in composing our movement, or what Adhitya (2013) refers to as the composition of urban rhythm. This relates strongly to Lefebvre's (2004) theory of rhythmanalysis and the embodiment of environmental rhythms surrounding us, which we measure against the metronome of our own internal bodies. According to Adhitya (2013), we should be composing our urban environment at the appropriate spatial scale in order to produce the rhythms that we desire to experience. Thus, to compose a stimulating rhythm for a pedestrian, we must design at the human scale. Gehl (2010) suggests that a good rate for stimulus-change is about once every five seconds. This means that, at a typical walking speed, the stimuli should change approximately every 5 metres. Gehl describes this using the example of typical small shop frontages in Copenhagen, which are 5 metres wide. Thus as a person walks past a succession of shops with different window displays they experience a change of scene at five second intervals. By designing with this as a guiding principle, we could make the environment more interesting, stimulating and enjoyable for pedestrians. On the other hand, if designing for a typical vehicular speed, a five-second stimulus change would only happen every 50 metres. This spatial scale would yield environments that are rather boring for pedestrians. For example, the rhythm of activity provided in Cat Street (Figure 1) provides a level of stimulus that is inviting enough for people to be there, even in the evenings. However, Grafton Way (Figure 2) provides little stimulation and thus remains a relatively empty passage through which people pass as quickly as possible. At night time, with even less lighting and activity, it may even become a place of fear and discomfort. Thus, in order to improve people-environment interaction and thus their urban experience, we must design, or rather compose, places with the appropriate rhythm.

Figure 1 Cat Street, Tokyo, Japan (see online version for colours)

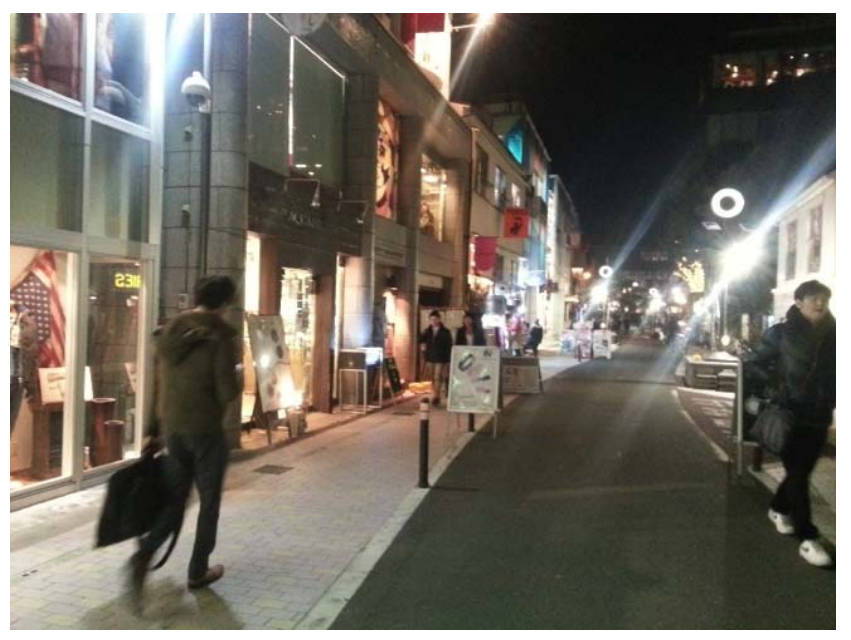


Figure 2 Grafton Way, London, UK (see online version for colours)

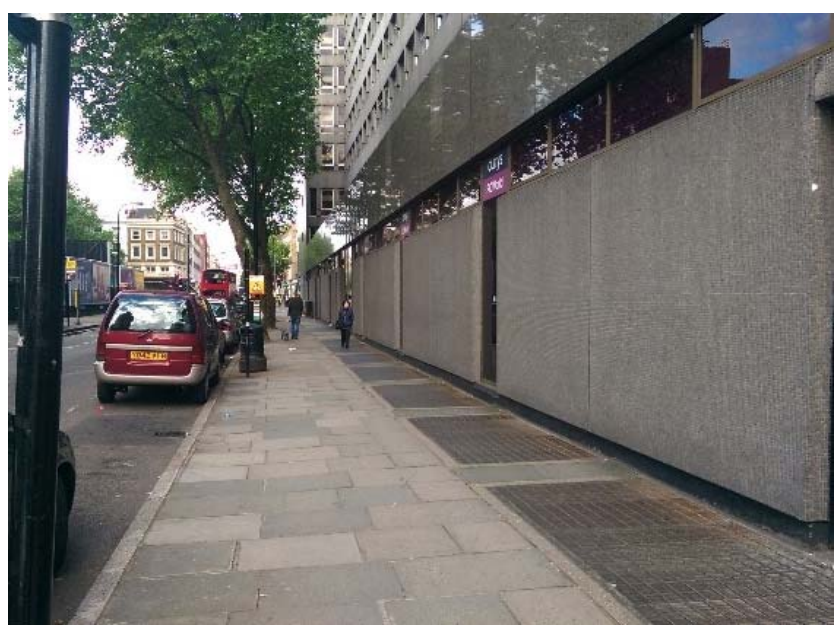

Walking is not only more likely due to interesting stimulation at an appropriate speed, but also strongly related to how comfortable the body feels in its environment. This is primarily dependent on the weather - whether it is hot or cold, sunny or raining, humid or dry, even low or high pressure. Everyone reacts differently to their environment and has different sensorial limitations to ambient temperature, humidity and pressure, not to mention psychological and emotional responses to weather. For example, in our work in Latin America, we found that many people were unwilling to walk because of the heat and humidity. However, on a sunny day in London, people take advantage of the opportunity to enjoy the sun (see Figure 3). Thus when we are composing our urban infrastructure, we should make sure to factor in people's responses to weather conditions.

Figure 3 Using a bench to enjoy the sun in London (see online version for colours)

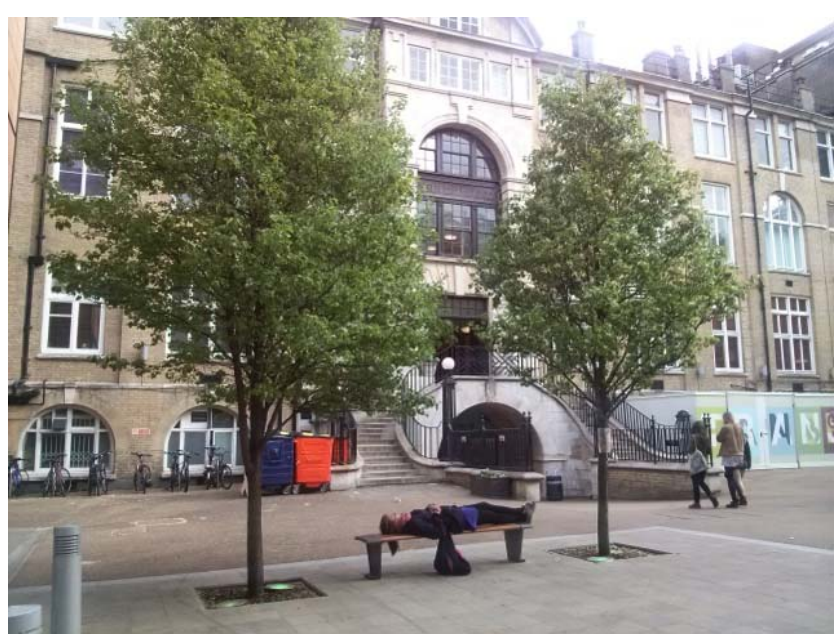




\subsection{Composing for waiting}

'Waiting' is defined as 'to remain in a place, defer one's departure, until something has happened' (OED, 1989). Waiting is purposive - we wait 'for' something to happen. It is not a desirable state - we do not want to wait for the sake of waiting, but because the endpoint of the wait will be something we desire or need, for example, waiting for a bus. However, our perception of time changes according to our activity - the time spent waiting for a bus is often perceived to be about twice as long as the actual amount of time that has passed (Tyler, in press). The implication that there is an endpoint to the period of waiting is important and distinguishes it from lingering, which will be discussed in the following section.

Waiting is an activity in which we often find ourselves obliged to partake. However, the design of our infrastructure means that this becomes, more often than not, a chore rather than a pleasurable activity. Waiting arises because the infrastructure has been unable to deliver its service at the moment that a person expects it. Thus the success of any infrastructure system is largely dependent on how the experience of waiting has been composed. A simple design solution is to provide seating for people to rest themselves and their belongings, which usually is quite a simple spatial exercise concerning the form and placement of the seat. However, universal composition calls for the design of the seating in a multisensorial, temporal way. Thus the view from the seat should be considered, as well as its surrounding soundscape and lighting conditions. It may also incorporate other activities, such as a coffee bar or book loan (see Figure 4), that can make waiting for a bus a pleasure rather than a chore. Universal composition aims to encourage multiple uses over time - a bus stop is thus not only a bus stop but a part of a person's experience of the urban realm, whether or not they are intending to catch a bus there.

Figure 4 Bus stop book loan for waiting passengers, Paris (see online version for colours)

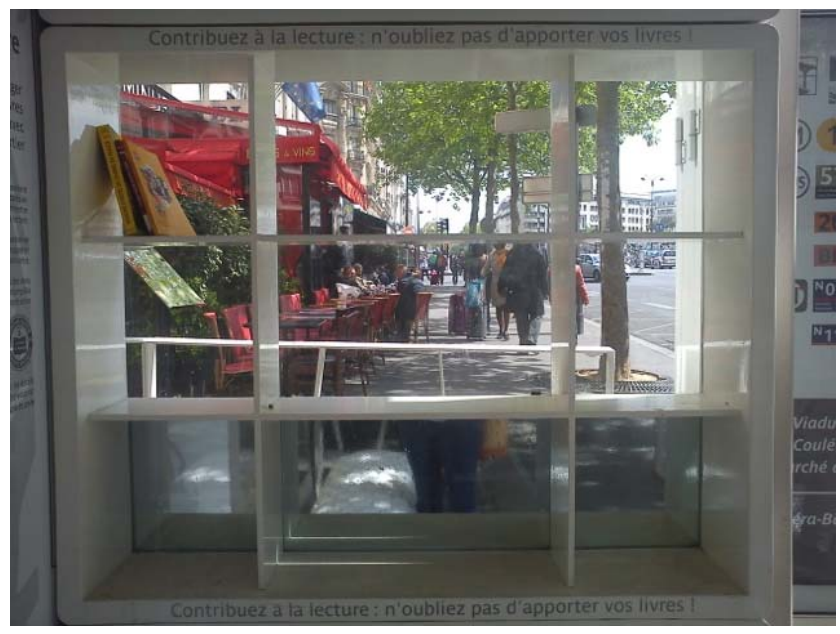

Such activities are, in effect, reducing the disparity between perceived time and actual time in the case of waiting. Another way to achieve the same outcome is by showing real-time arrival information, which seeks to provide a reminder of the passage of clock time. By shortening the perception of time spent waiting in public transport infrastructure 
such as bus stops, designers could make it less of a disincentive to use such infrastructure systems and more attractive as a transportation option. This means changing the perception of time spent waiting towards something more like lingering, where the activity is not constrained.

\subsection{Composing for lingering}

Lingering is an important activity, and is defined as "stay[ing] on or hang[ing] about in a place beyond the proper or usual time" (OED, 1989). We use the word 'linger' in a very specific sense. As discussed in the previous section, this is not the same as 'waiting' and neither is it the same as other words which are used to describe a static presence in a space, such as 'loitering' or 'lurking'. Just as waiting signifies that there is an end objective - for example the arrival of a bus - so loitering and lurking have a sense of ulterior motive, which is usually negative. Lingering, on the other hand is a positive experience, both for the lingerers and the society and social space in which they linger. It is necessary therefore to design carefully for lingering so that it does not also encourage loitering or lurking. The best way of achieving this is to design the space to encourage a reasonable number of lingerers - the presence of others is one of the best deterrents to loitering or lurking. This concept of passive surveillance is used in a number of environments such as shopping streets, where the presence of shoppers discourages people who wish to do bad things. So the design should create a sense that it is a great place to be, that people want to be there to enjoy it and that the serendipity of chance encounters - with people, events, objects - provides positive interest for the greater good of society.

Urban design should ideally cater for lingerers because they provide a human element to the urban realm, one that pauses, moves, breathes, observes and comments and which softens the hard edges of built infrastructure. Figure 5 shows a group of lingerers in Cartagena, Colombia, who are just passing the time of day, softening the edge between the wall and the street, providing warmth and surveillance - but also providing a presence with which other people can interact, thus creating the opportunity for casual social interactions which make the city feel like a place for people. The sense of wanting to do this is so strong that they happily create the spaces for lingering - in this case using the doorsteps as improvised seating - and these can be dynamic - the lingerers are in the shade and would move as the sunlight bears upon them. There is no sense that this activity has a programmed finishing time, yet there is a real sense of a people-space over time. The design of the doorsteps was not intended for this purpose - the people have taken over the design for their own purposes. Figure 6 shows people in Buenos Aires, with the absence of a formal street bench, using the bollards as seating. In Figure 7, a piece of public art is inviting enough for a person to linger, lean and watch a tango performance in the public place nearby. The canons embedded into the streets of Cuba provide a similar role (see Figure 8), creating a soft edge separating people from cars that is full of bustling people rather than hard barricades and fencing. It is a good challenge for designers to aim to design such permissive infrastructure, where people are able to make it their own, use it for their own pleasure - but also where this creates a sense of social space which is owned by everyone and no-one at the same time.

Lingering is much more of an act of choice than waiting. Because it has no expected end time, it does not relate to perception of time, except perhaps after the event, when we might be surprised about how much time we have just spent apparently doing nothing. 
Rather, it is a sign that people are enjoying themselves in a certain space. However, although bollards and stairs may function as nice places to sit and stay, urban infrastructure designers can help make the urban realm more welcoming for people to do through universal composition. For example, by providing more comfortable seating which can be adapted to people's wishes, encouraging them to enjoy their local environment, and therefore linger for. Unlike waiting, lingering cannot be predetermined but it can be promoted by providing the appropriate infrastructure for people - adults and children alike - to want to stay longer (see Figure 9). Figure 10 shows an example of all three activities taking place at a bus stop in London.

Figure 5 Lingering on the stairs in Cartagena, Colombia (see online version for colours)

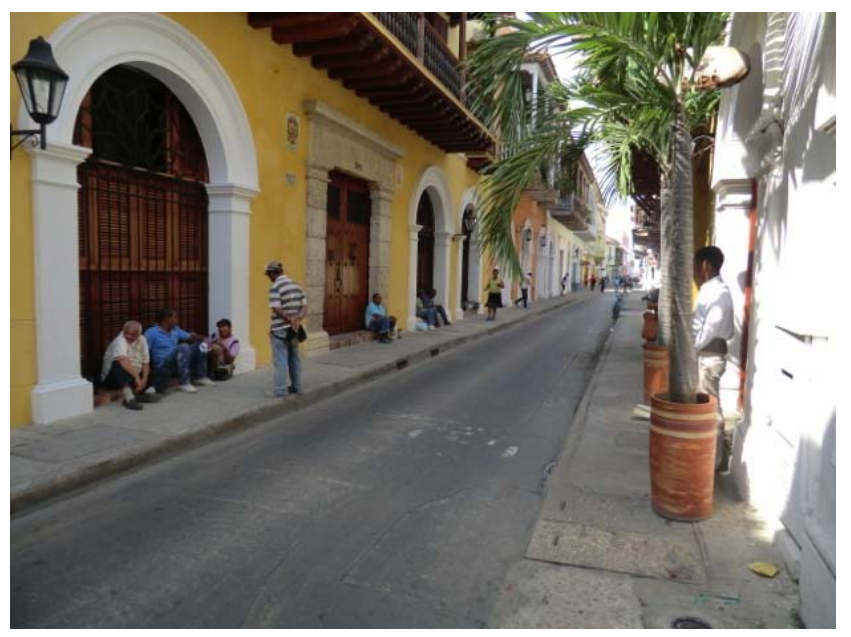

Figure 6 Lingering on bollards in Buenos Aires, Argentina (see online version for colours)

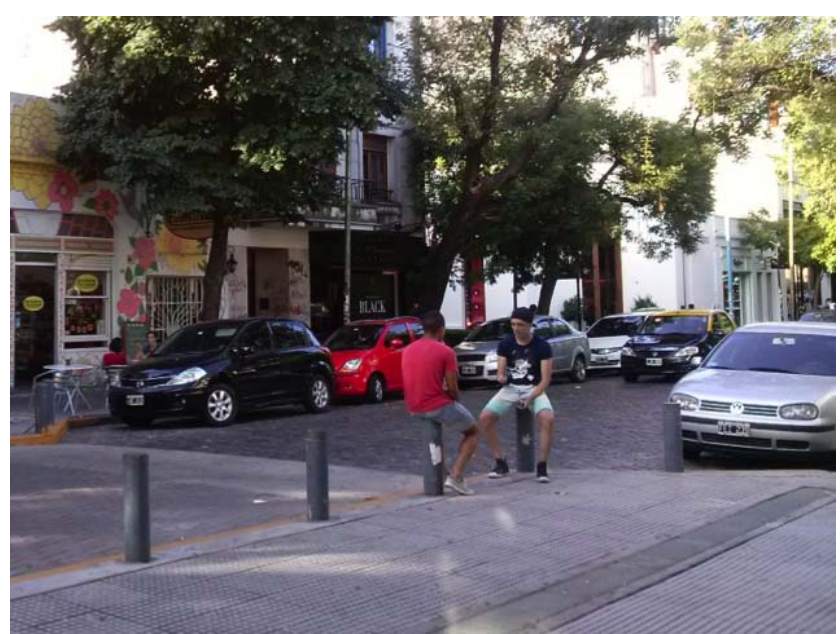


Figure 7 Providing places to wait and lean, Buenos Aires (see online version for colours)

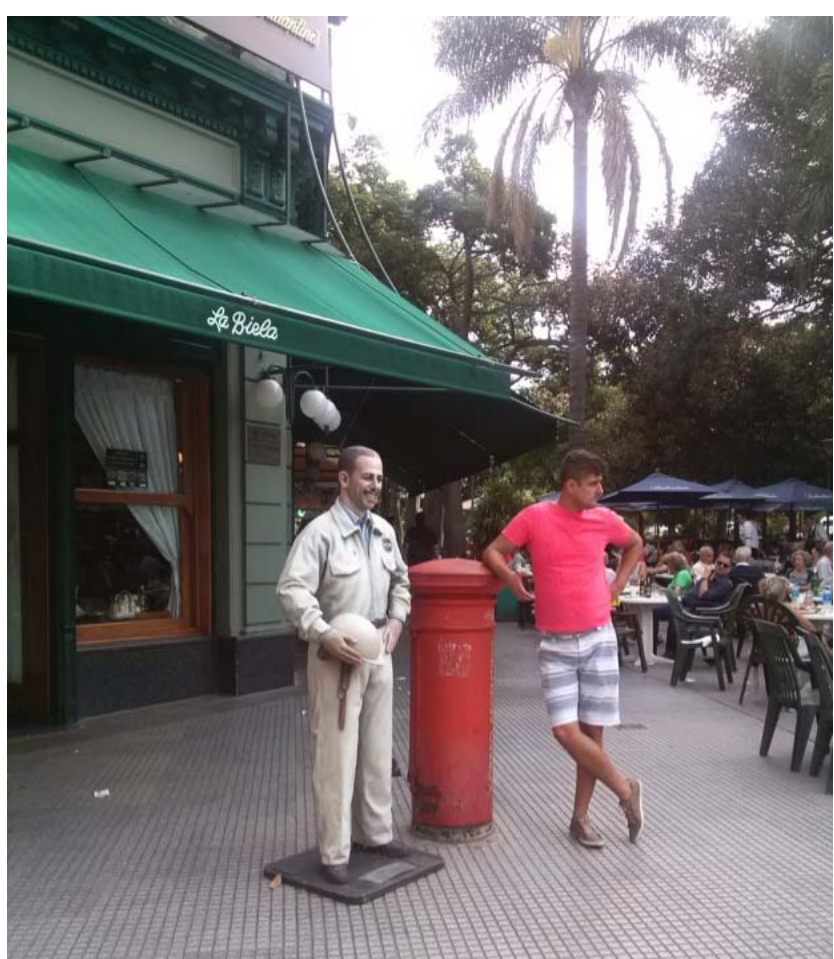

Figure 8 Leaning on canons, Havana, Cuba (see online version for colours)

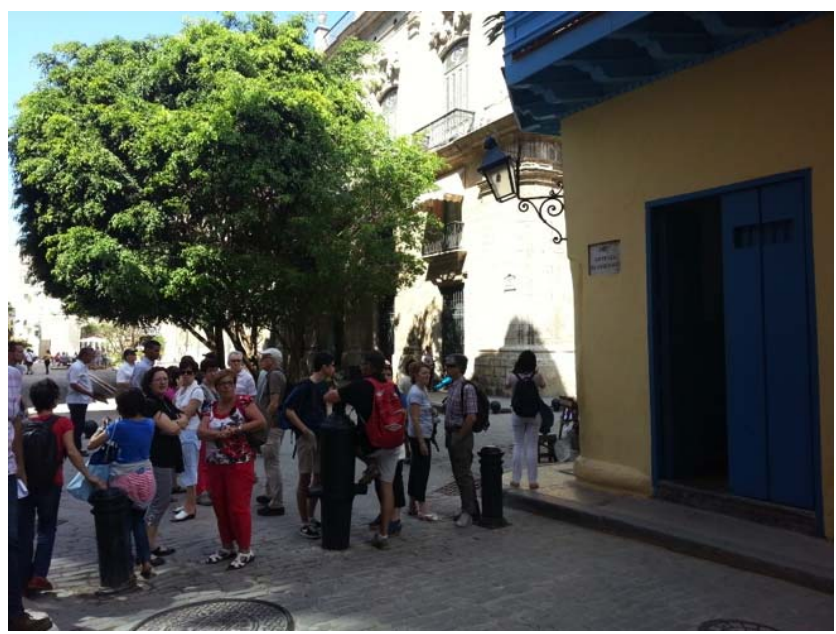


Figure 9 Thinking about providing places for children to linger as well as adults in Palermo, Buenos Aires (see online version for colours)

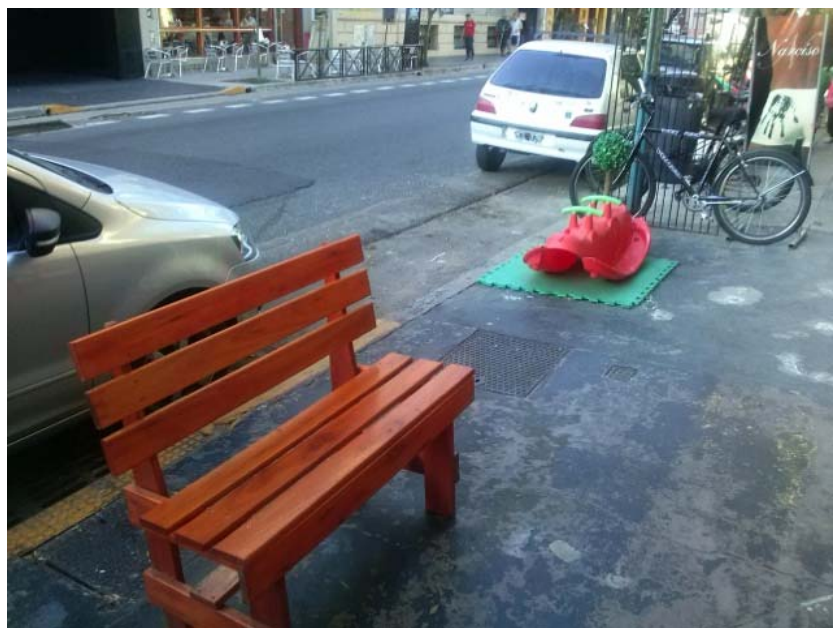

Figure 10 People walking along a street, waiting in or near a bus shelter, and a lingerer, London, UK (see online version for colours)

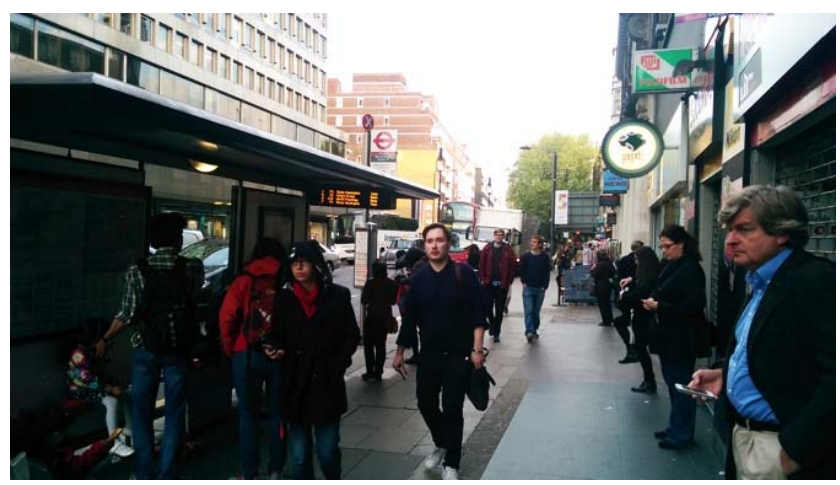

\section{Walking, waiting... and lingering in London}

The Universal Composition Laboratory at University College London (otherwise known as UCL-squared) aims to implement the principles of Universal Composition in its various urban design projects in order to improve societal wellbeing (UCL-squared, 2014a). In this section, we will discuss some examples which UCL-squared has implemented in London concerning bus stops, which are a numerous and important element of the city's infrastructure system. They must mediate the 'phase change' between walking and waiting, being the point at which we transform from pedestrian to passenger, and perhaps even succeed in becoming places to linger. This temporal change must be carefully composed in time as well as space in order to render the city's bus network an attractive and effective mode of transportation. 


\subsection{Interactive bus stops}

The first example consists of two interactive bus stop installations in Regent Street in London on 22 June 2014. On this day, the street was closed to traffic for the 'Day of the Bus' (Transport for London, 2014), and Transport for London granted permission to UCL-squared $^{1}$, in collaboration with Goldsmiths University ${ }^{2}$, to transform two of its bus stops. Through a series of multisensorial interventions, both low and high tech, we sought to change people's perception of the bus stop from somewhere they have to wait, to a place where it is great to linger. Through this, we hoped to encourage the usage of the bus system.

\subsubsection{The musical bus stop}

The first bus stop - termed the musical 'bus stop' (shown in Figure 11) - was transformed into a collaborative musical instrument which could be played by members of the public. The seats were fitted with pressure sensors which were linked to digital synthesisers, creating a series of 'musical chairs'. When sat on, different musical tracks where activated, surprising unsuspecting members of the public. When activated together, the whole composition would be played.

Figure 11 Collaborative music-making at the 'musical bus stop' (see online version for colours)

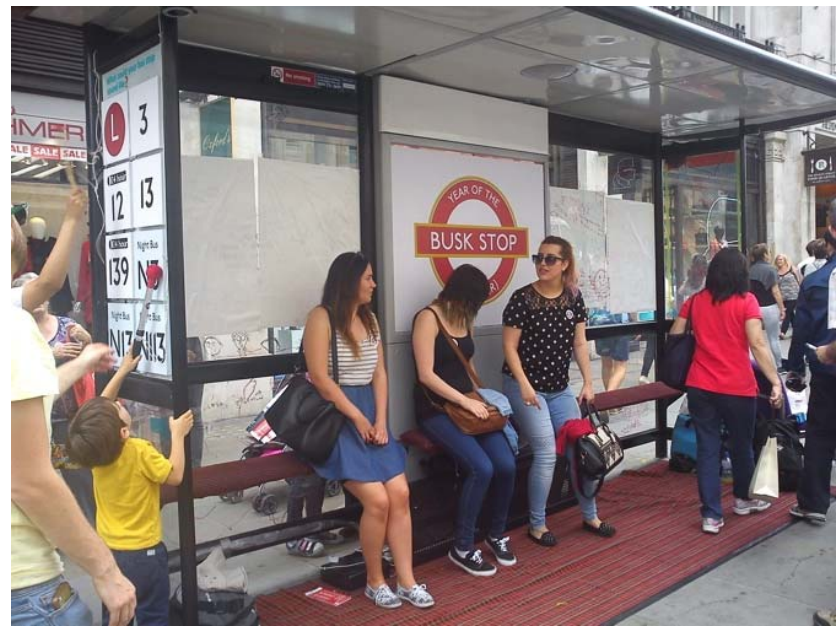

Musical signage (see Figure 12) advertising the bus routes was also created on the bus stop panel, which is normally reserved for advertising to passing car drivers. This information is strategically positioned at eye-level and is thus more visible to pedestrians than high up on the usual bus stop flag. Each bus route was allocated a different sound and the sign could then be played like a percussion instrument. The signage was then tuned to the seats, and thus while some people were playing musical seats, others could be playing the percussion in accompaniment. Together they could produce a collaborative musical composition. The idea was to encourage people waiting at the bus stop to participate in the formation of their public space - aural as well as visual - as well as to interact with each other. 
Figure 12 Musical signage on the advertising panel (see online version for colours)

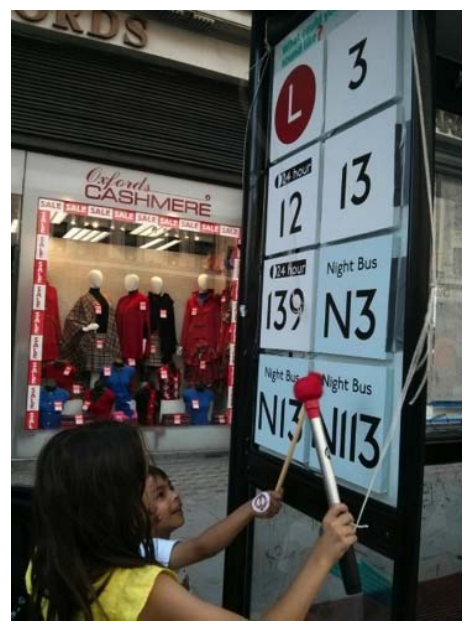

\subsection{3 'Design your own' bus stop}

The second interactive bus stop in Regent Street allowed the public, through a series of practical visual activities, to physically redesign it themselves (see Figure 13). By asking them what their bus stop could be, we played with the 'image' of a bus stop and thus the perception of its function(s). The objective was to position the passer-by to view this everyday piece of infrastructure as an important compositional element of their urban environment which can change over time. The public was invited to decorate it in various ways, as well as to arrange different types of furniture and other objects to create the sense of different living spaces, for example a 'living room' or an 'office space'. By seeing the bus stop as a place where we can carry out our normal everyday activities, like relaxing and working, our intention was to make 'waiting' for the bus a more stimulating and enjoyable activity, and perhaps become a place to linger. By creating positive people-environment interactions relating to the bus stop infrastructure.

Figure 13 Designing one's own bus stop (see online version for colours)

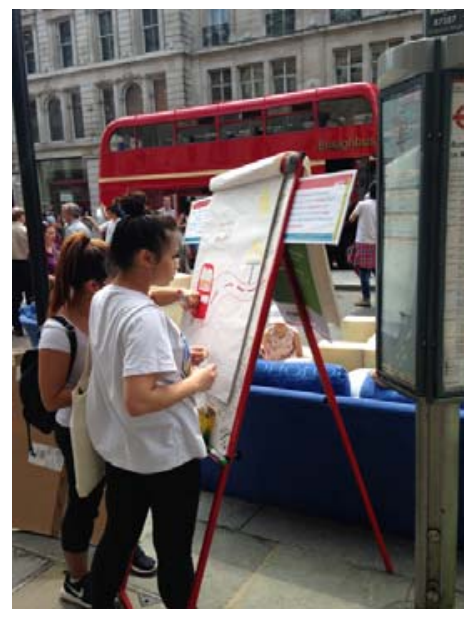


Through each of these interventions, we hoped to use universal composition to change the perception of a bus stop from being an everyday urban object to becoming a pleasurable experience in the urban realm. This event was used as a starting point for further multisensorial design interventions to other bus stops in London, which UCL-squared are currently developing with TFL. Using bus stops as strategic points of intervention in various parts of London, we hope to create points of stimulation in the city, as well as interesting places to wait and linger. By composing positive people-environment interactions relating to the bus stop infrastructure ${ }^{3}$, we aim to encourage greater use of the bus system.

Such interventions at key points in the precise yet widely-spread network of bus stops can be seen as an example of 'urban acupuncture', an increasingly-popular approach to urban regeneration involving the stimulation of strategic points in the urban system to improve its surrounding urban flows (Lerner, 2014). The idea is that a small intervention at a key point can yield benefits at a much larger scale in the city. For example, by making the use of the bus system more attractive at a local bus stop means that people are more likely to use the bus rather than drive their car. On a large scale, this would help reduce the traffic flows throughout the city and the resultant greenhouse gas emissions.

Figure 14 Relaxing with various pieces of furniture in the bus cage (see online version for colours)

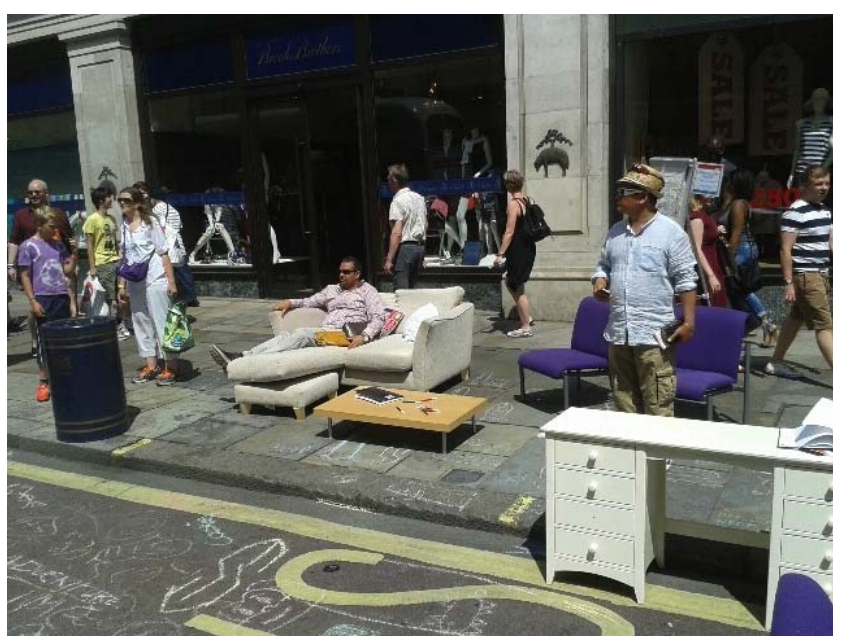

\section{2 'Edible' bus stops}

The concept of 'Edible bus stops' started life as a guerrilla gardening initiative led by a group of local residents in South London (Figure 15) (EBS, 2014). The residents reclaimed a piece of derelict land near a bus stop to create a garden and provide a more pleasant environment by introducing aromas, colours and tastes. A living extension of the infrastructure system, it looks and smells differently according to the seasons and contributes to the surrounding microclimate. UCL-squared intends to apply this idea to central London by constructing an 'edible bus stop' outside its main entrance in Gower Street, a busy transport corridor with limited pedestrian space (see in Figure 16). The plan is to redesign the bus shelter in combination with a 50 metre-long garden between the 
footway and the university building. The proposal aims to use plants which are suitable for the area and have the best impact on local wildlife, as well as generate better health for commuters by improving the surrounding air quality. With the bus stop becoming a living, multisensorial and dynamic element in space and time, we aim to stimulate people-infrastructure interactions which will lead to more positive behavioural outcomes regarding public transportation in central London. This project is currently in the stages of planning approval.

Figure 15 The edible bus stop in Lewisham, London (see online version for colours)

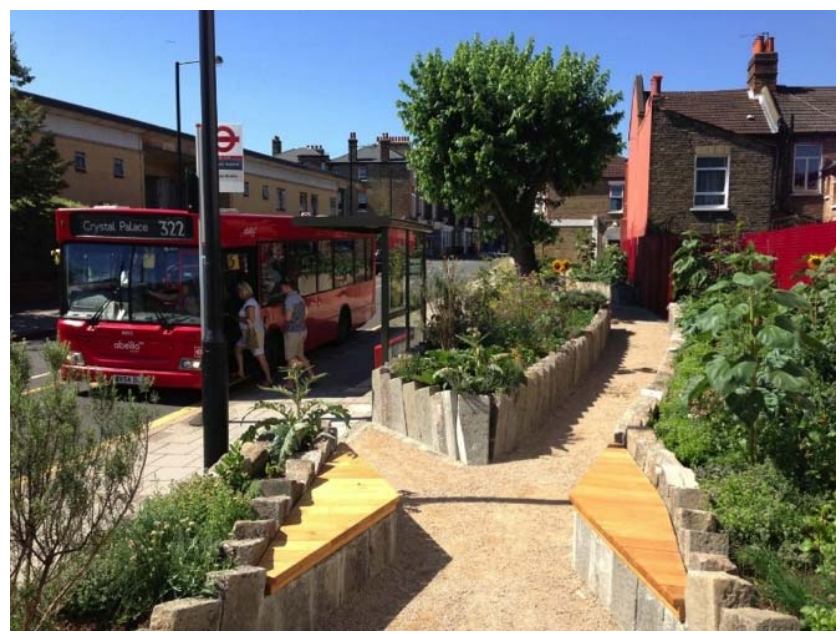

Figure 16 Site of a future 'edible bus stop', Gower Street, London (see online version for colours)

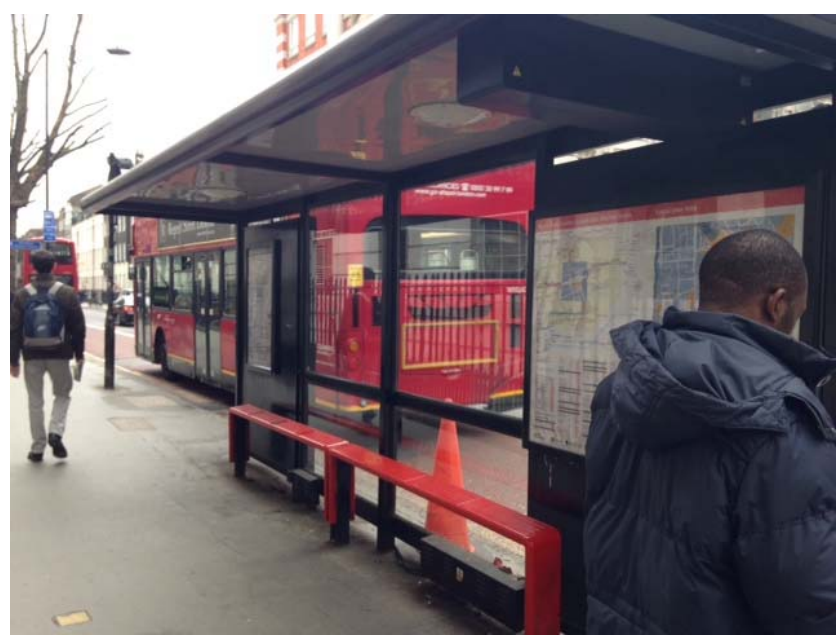




\section{Walking, waiting and lingering in Latin America}

In this section we will discuss walking and waiting in three cities in Latin America, where UCL-squared has been conducting workshops with transportation professionals on improving mobility to address climate change. Unlike London, where car-usage is currently decreasing, in these cities it is rapidly increasing. A key component of these workshops involved helping participants to recognise the small details in their cities which were creating such urban problems as traffic jams and air pollution. Utilising the approach of universal composition and recognising that human-environment interactions are key to the success of any infrastructure system, in this section we will discuss how walking, waiting and lingering can be composed to improve public transportation usage.

\subsection{Walking in Latin America}

Walking is very unpopular in many cities in Latin America - people avoid walking as a mode of transportation as soon as they are able to buy a car, and the result is increasing traffic problems and carbon emissions. One reason for the wish to drive is the quality of the pavement - lacking continuity and full of barriers and holes, the experience can be described as being more like an obstacle course (see Figures 17 and 18). With such an uneven surface, establishing any sort of rhythm is extremely difficult and makes walking a challenging - and sometimes dangerous - experience rather than a pleasurable one. However, those who cannot afford to buy a car must continue to walk and are reliant on the largely inefficient public transportation system, which makes mobility an uncomfortable and often time-consuming process. It also helps to create the desire to buy a car as soon as possible in order to escape these difficulties. For people who are blind or disabled, it makes mobility almost impossible. Even where aids to mobility are installed, these do not always function as well as they should due to flaws in their implementation. For example, Figure 19 shows a tactile guidance strip, which is intended for visually-impaired people, leading into a bollard, waiting for them to trip over it.

Figure 17 The pavement in Santa Marta as an obstacle to walking (see online version for colours)

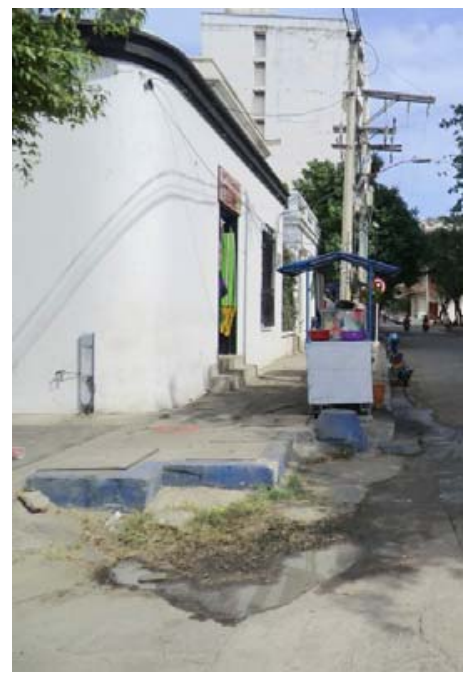


Figure 18 An electric pole blocking the path of pedestrians (see online version for colours)

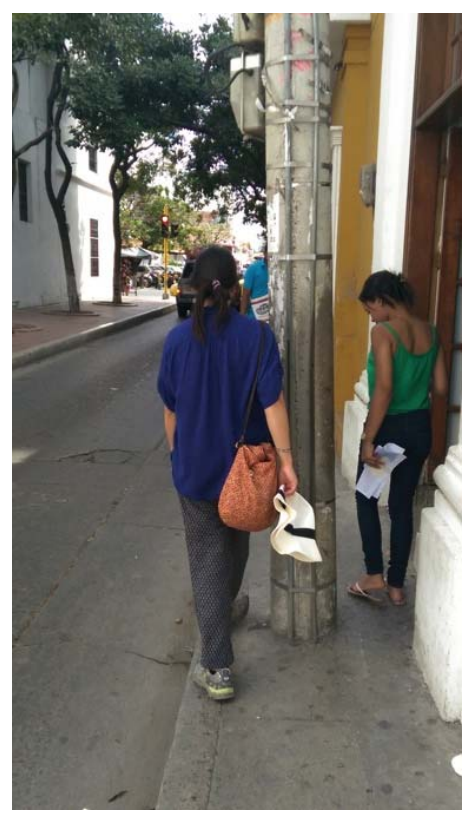

Figure 19 A blind strip leading into a bollard (see online version for colours)

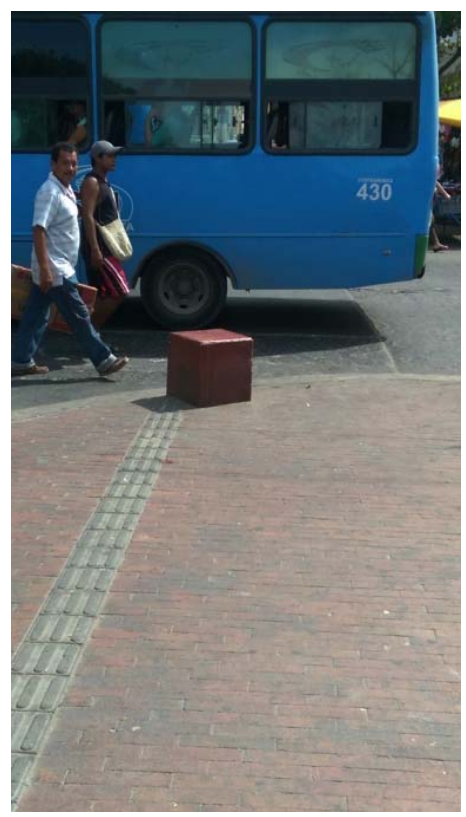

One reason for the condition of such pavements can be attributed to the overwhelming privileging of motorised vehicles over the pedestrian. It is clear that motorists, and traffic planners, are accustomed to assuming the right of way when designing road networks. They assume this hierarchy even when crossing or parking their vehicles on footpaths 
and blocking pedestrian flow (see Figure 20). However, such infrastructure design contradicts the role of infrastructure as the support for social wellbeing. Through small but simple interventions, such as the sign installed by our workshop participants in Figure 21, we hope to remind people and designers of this fact and help the pedestrian regain their rights to the street.

Figure 20 Cars parked on a footway that has been heavily damaged by parking (see online version for colours)

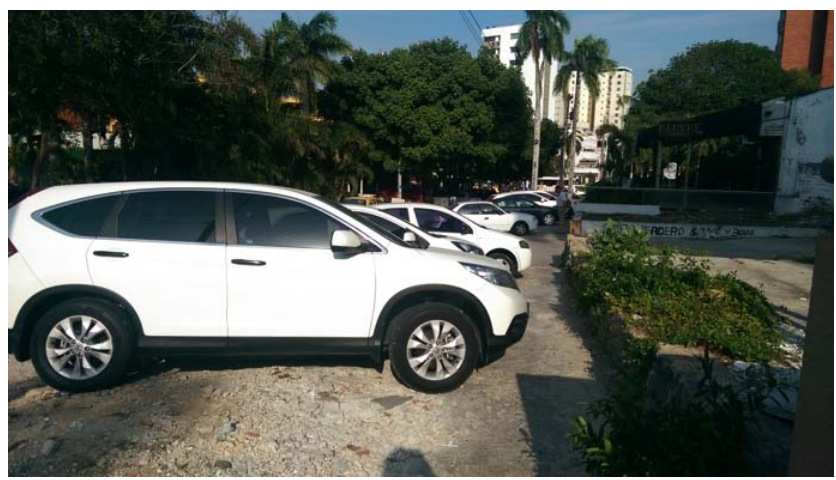

Figure 21 A street sign in Barranquilla demonstrating the hierarchy of vehicles over pedestrians, and our intervention attempting to regain the rights of pedestrians (see online version for colours)

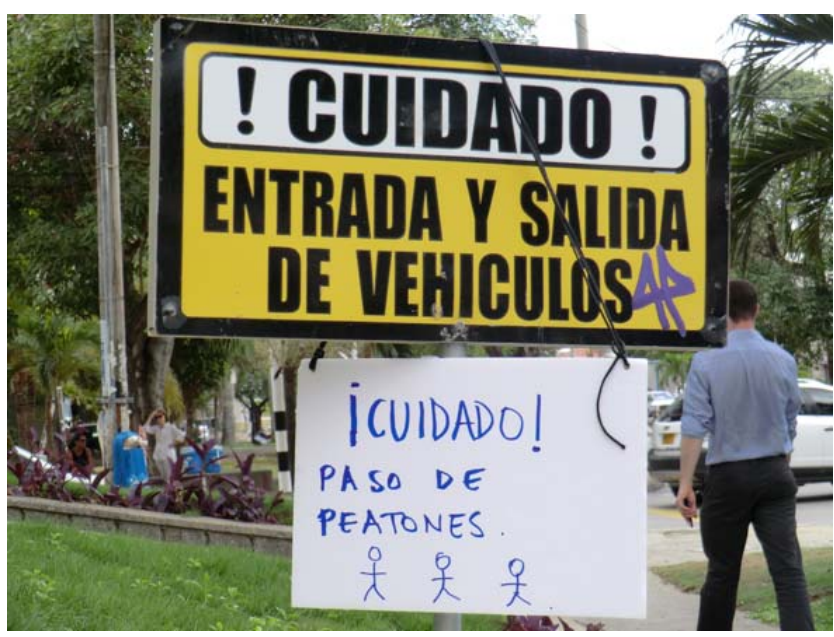

In addition to the quality of the pavement, another excuse often given by the participants in our workshops for not walking was the hot and humid weather. In recent workshops run by UCL-squared concerning mobility in Barranquilla and Santa Marta (on the Caribbean coast in Colombia), as well as Panama City, a common excuse for participants not to walk was because it was too hot and that they would arrive sweaty at work. This included people who lived just a ten minutes walk away from their offices. In the case of Barranquilla, the weather used to be more bearable when the native trees still grew in the streets. However, due to a desire by a previous Mayor to make the city look like Miami, 
many of these trees were replaced by more 'aesthetically pleasing' palm trees. However, such a seemingly trivial decision concerning the aesthetics of the landscaping has had a massive impact on increasing the city's ambient temperature, and the consequences are unfortunately influencing the decisions and behaviour of its inhabitants today.

Figure 22 A native tree and the workshop participants' intervention highlighting its effect on the city's microclimate (see online version for colours)

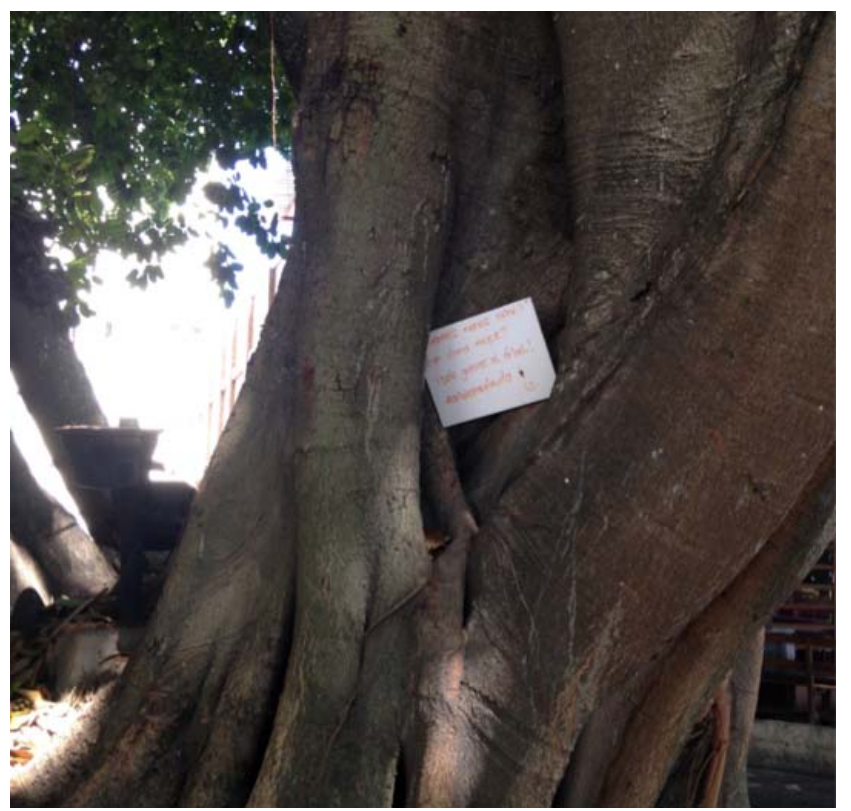

Figure 23 The sign reads: "Do you feel less heat? A better climate? Thank the tree!" (see online version for colours)

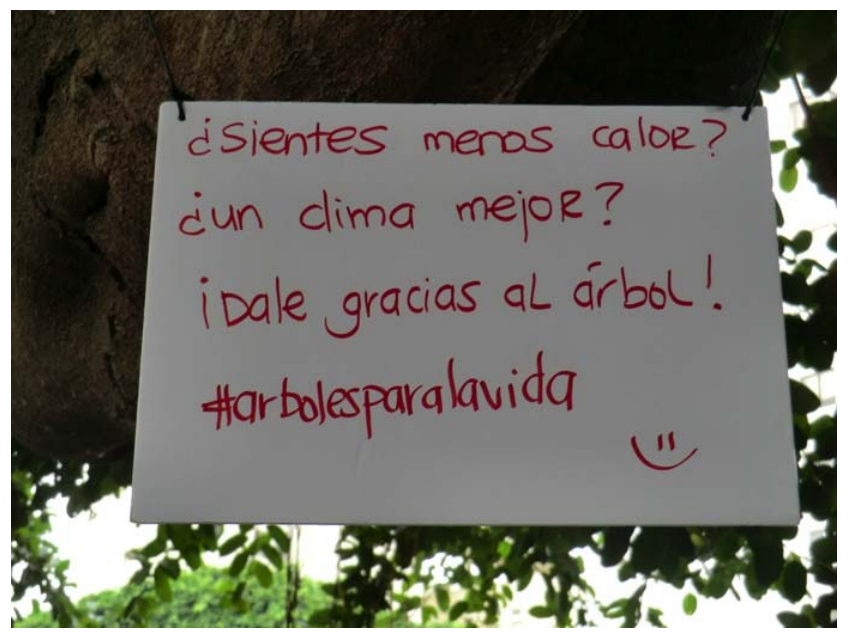


Figure 24 A carefully-composed micro-climate allowing people to enjoy the hot outdoor environment of Buenos Aires (see online version for colours)

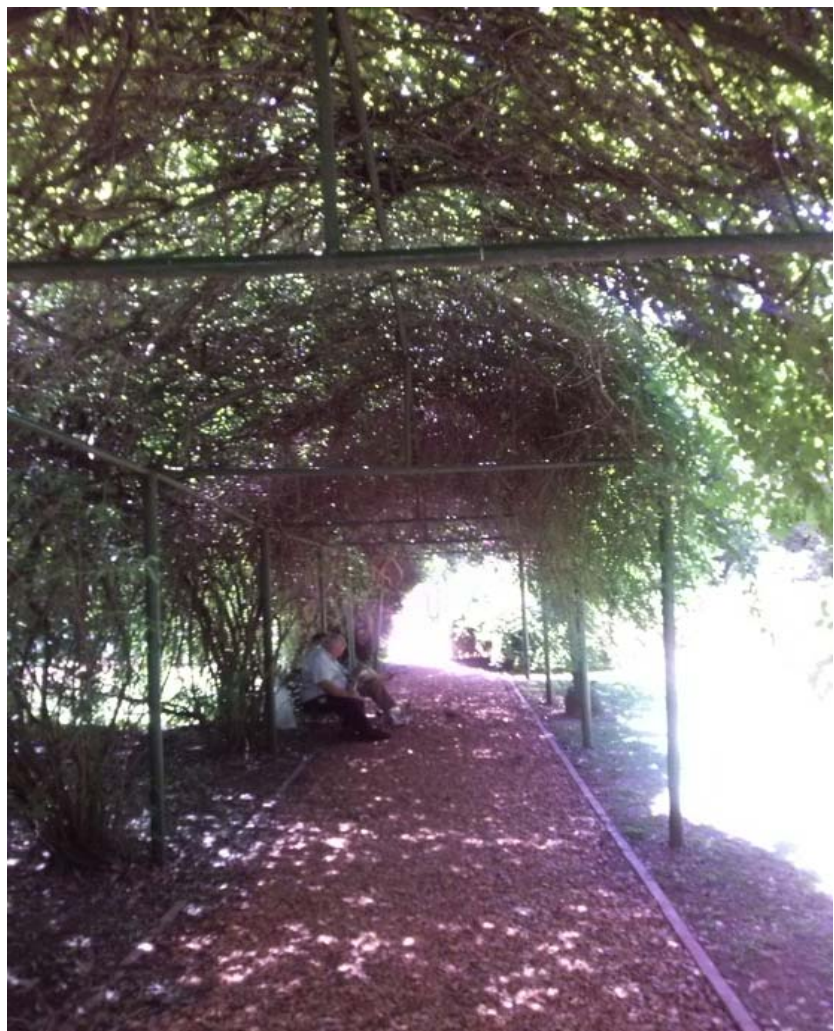

For example, the temperature under the native tree shown in Figure 22 is around two degrees less than the area beyond the tree's shadow and the water vapour produced by the photosynthesis process helps to maintain a feeling of being relatively cool. In addition to directly improving air quality (trees absorb carbon dioxide and emit oxygen), the trees could also reduce carbon emissions by encouraging walking and reducing car usage. It is clear that weather conditions make a big impact on one's choice of transport mode and must be considered in the design of a city's infrastructure system. The participants of our workshop recognised the importance of providing conditions for walking, whatever the design of the public transport system, and highlighted the effect with the sign in Figure 23. It is up to urban designers and landscape architects to re-establish urban micro-climates through the careful composition of pedestrian infrastructure with appropriate vegetation and shading, such as that shown in Figure 24.

\subsection{Waiting in Latin America}

Bus stops in Barranquilla and Santa Marta, even where they exist at all, also leave much to be desired in terms of promoting waiting. Like walking, waiting in the sweltering weather conditions is undesirable. In addition to this, they also lack signage and information, and often even the bus shelter itself. The question of 'why wait?', thus becomes also one of 'where to wait?'. 
Figure 25 UCL-squared's live 'Paradero Musical' in Santa Marta, relying on local participation (see online version for colours)

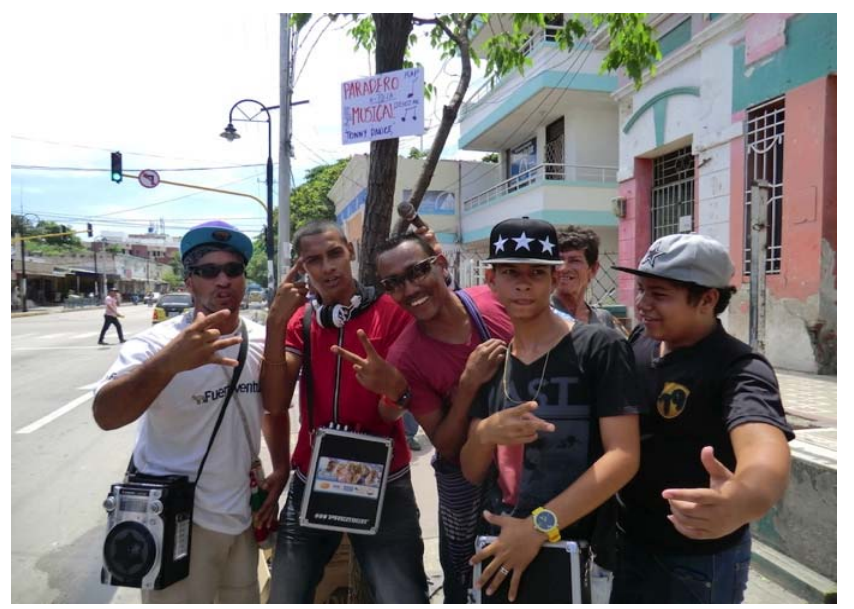

Figure 26 Making waiting fun in the metro system in Buenos Aires (see online version for colours)

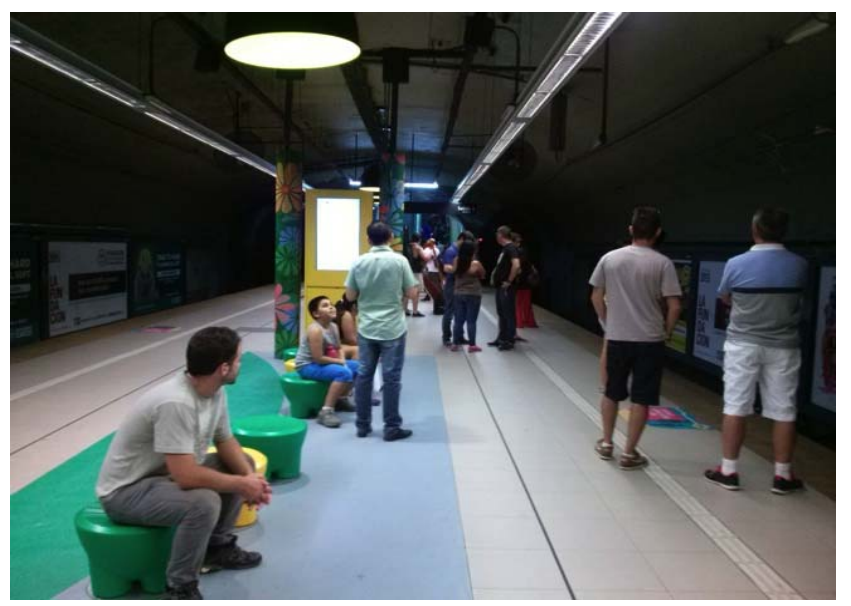

In Barranquilla, the bus stops are street poles, often without any indication of the bus stop destination or direction. In Santa Marta, in the absence of many bus stops, much of the system still relies on local knowledge of which bus to catch and where it will take you. Although the municipality of Santa Marta understands the limitations of this system and is currently in the process of developing a more comprehensive and communicative bus system, the question in the mean time still remains 'where to wait?'. In order to function as part of its wider public transport infrastructure system, the integration of the bus stop in its urban environment is critical. It is important, as in the case of London, that it is considered and adopted as a part of the public domain where people desire to be and therefore are more willing to wait. During UCL-squared's workshop on 'Recreating Mobility' in Santa Marta in August 2014, participants created another musical bus stop a 'Paradero Musical' - together with a local youth rap band (see Figure 25). Identifying an appropriate place where people accumulate to wait is important for ensuring public 
transport usage. The next stage is in providing the appropriate infrastructure which contributes to more inviting environments for waiting so that public transport usage is encouraged (see Figure 26).

\subsection{Lingering in Latin America}

Lingering in the hot climate of Latin America requires careful consideration. One common problem discouraging waiting and lingering outdoors is the current positioning of street benches under the hot sun, as often encountered in Santa Marta (Figure 27). Needless to say, these burning concrete seats are not the most popular place to linger. Fortunately, this is a relatively simple and inexpensive problem to solve. As implemented in Buenos Aires (see Figure 28), the coordination of street benches with trees has produced positive results, indicated by an increase in the number of people lingering in public outdoor spaces. This could also have an impact on the number of people walking. Through the thoughtful composition of small urban details, this important social activity can be easily supported and the use of public infrastructure thus encouraged. As discussed in Section 2 and shown in Figures 5, 6, 7 and 8, lingering is an activity which, when appropriate conditions are available or adopted, is enjoyed by many people in Latin America. The design of infrastructure to encourage lingering thus has great potential to increase people's enjoyment of their city.

\section{Making the universal, personal}

Public engagement in the design process as well as future appropriation of public transport infrastructure, such as bus stops, is important for the community to feel a sense of ownership of their public realm. While designers can help in urban place-making, it is the people who use the space that should have the most to say. Many examples of community appropriation of the city's public infrastructure can be seen in the area of Palermo in Buenos Aires, for example, by decorating individual bus stops (Figure 29), painting street benches (Figure 30) and decorating signage (Figure 31).

Figure 27 Hot benches versus trees in Santa Marta (see online version for colours)

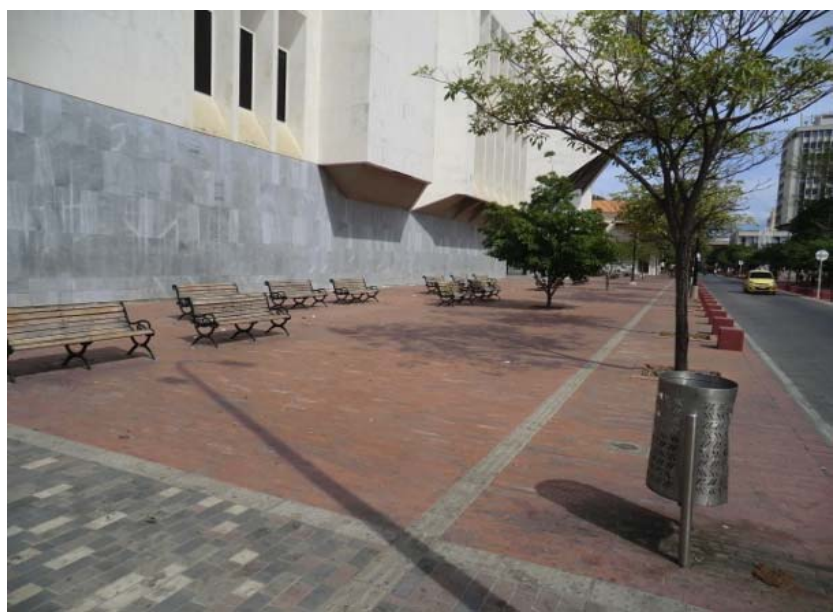


Figure 28 Problem resolved in Buenos Aires (see online version for colours)

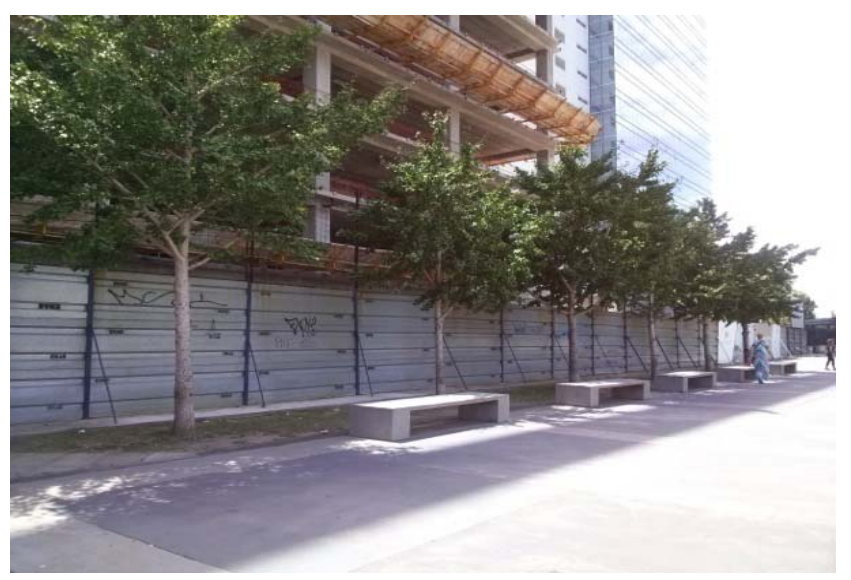

Figure 29 Customised bus stop by nearby graphic design business, Buenos Aires (see online version for colours)

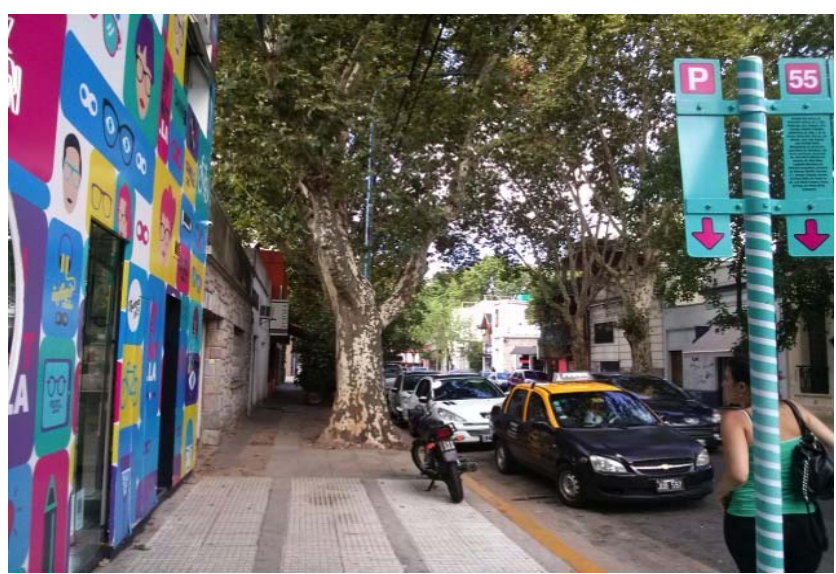

Figure 30 Decorated street bench, Buenos Aires (see online version for colours)

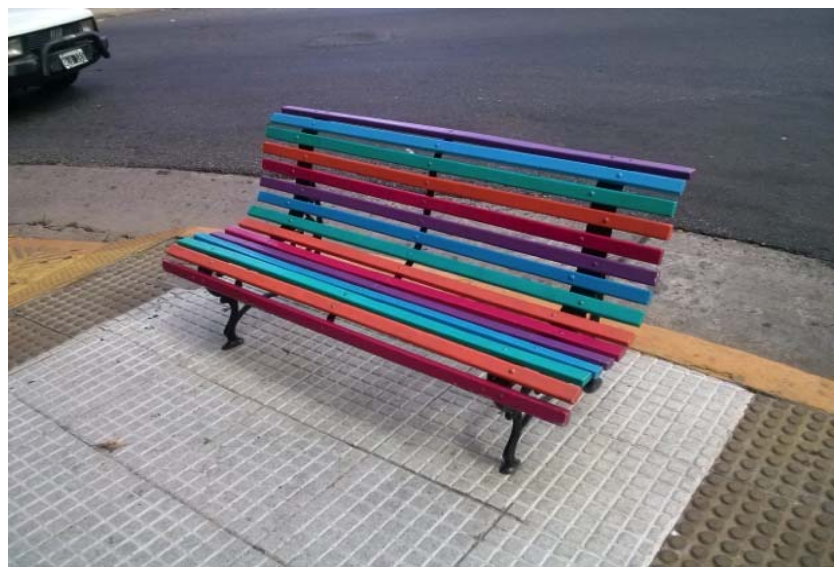


Figure 31 The community decorating the municipality's public infrastructure signage in Palermo, Buenos Aires (see online version for colours)

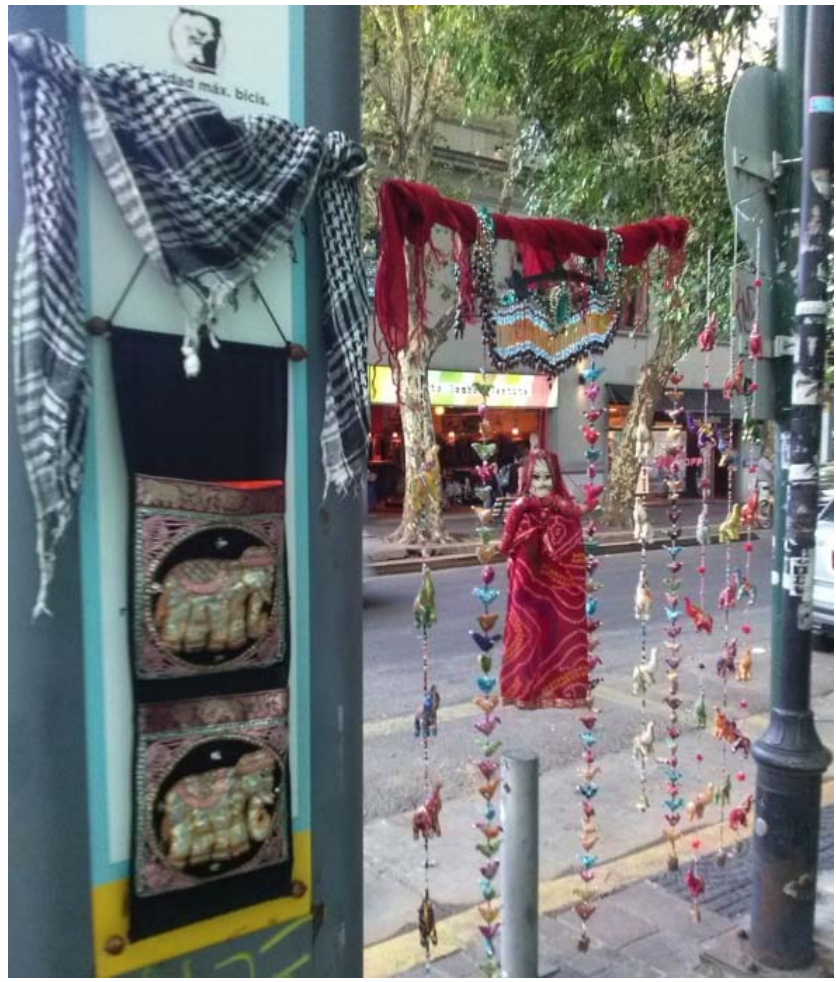

\section{Conclusions}

In many capital cities such as London, reducing traffic congestion by encouraging public transport usage is always an issue. Making it a more attractive option through the creation of interactive, enjoyable experiences will help do so while also improving the quality of the public domain.

The three cities in Latin America discussed in this paper are currently in the process of trying to reduce their greenhouse gas emissions and developing their public transport systems: Barranquilla with its recent BRT; Santa Marta and its future bus system; and Panama City and its current metro developments. However, in order for such large-scale - and costly - infrastructure systems to be functional and successful, the consideration of the small, human-scaled details is critical. It is clear that a bus, BRT or metro system that cannot be easily understood or reached will have fewer commuters than one which is well connected to the rest of the urban fabric. Similarly, public transport inevitably involves waiting - and expecting people to wait in uncomfortable conditions will make it less popular than in comfortable, interactive and stimulating environments.

In order for infrastructure to support the improvement in societal wellbeing, it is thus necessary to consider our interactions with it from the perspective of the sensing individual. In order to be used, infrastructure should be considered as a provider of 
pleasurable experience, rather than something that is imposed. At UCL-squared, we believe that positive behavioural change starts from positive experiences, and that the dynamic, multisensorial design of our people-environment interactions is the key. Our interactive bus stops in London are an example of rethinking the design of one element in a large-scale network. Spreading this small-scale intervention across the whole of the London bus network thus has the potential to make a large-scale impact. Our interventions and experiences in Latin American cities also show that it is possible to make big changes by first identifying small but important opportunities and implementing bottom-up, low-budget interventions.

Through our discussion of walking, waiting and lingering as three basic aspects of a person's interaction with the street environment, we have shown them to be activities that could be composed in a way to change the way people think about their urban infrastructure. Using the infrastructure to change the perception of these activities can help to change people's perceptions of the city as a whole and thus make a positive impact on societal wellbeing as well as enhancing the wellbeing of individuals. By applying the principles of universal composition to these seemingly small but numerous infrastructure elements, UCL-squared aims to improve the perception of our next generation infrastructure systems, and thus promote sustainable and positive behavioural change.

\section{References}

Adhitya, S. (2013) Sonifying Urban Rhythms - Towards the Spatio-Temporal Composition of the Urban Environment, PhD Thesis, Paris, Venice.

EBS (2014) [online] http://www.theediblebusstop.org/ (accessed 28 May 2014).

Gehl, J. (2010) Cities for People, Island Press, Washington, DC, USA.

Lefebvre, H. (2004) Rhythmanalysis: Space, Time and Everyday Life, Continuum, London.

Lerner, J. (2014) Urban Acupuncture, Island Press, Washington, USA.

OED (1989) Oxford English Dictionary, Oxford University Press, Oxford, UK.

Transport for London (2014) [online] http://www.tfl.gov.uk/campaign/our-events (accessed 28 May 2014).

Tyler, N. (in press) Accessibility and the Bus System: How Buses can Transform the World, ICE Publishing, London, UK.

UCL-squared (2014a) Universal Composition Laboratory [online] http://www.cege.ucl.ac.uk/arg/ ucl-squared (accessed 28 May 2014).

UCL-squared (2014b) The Bus Stop: London's Agent of Change [online] http://www.youtube.com/ watch? $\mathrm{v}=$ Y61W1kD-o9U (accessed 11 November 2015).

\section{Notes}

1 Nick Tyler, Sara Adhitya, Liliana Ortega.

2 Alexander Brigden, Matthias Moos.

3 For examples of this feedback, see UCL-squared (2014b). 